\title{
Monoclonal Antibodies Detect a Single Amino Acid Difference Between the Coat Proteins of Soilborne Wheat Mosaic Virus Isolates: Implications for Virus Structure
}

\author{
Jianping Chen, Lesley Torrance, Graham H. Cowan, Stuart A. MacFarlane, Gerald Stubbs, and T. Michael A. Wilson
}

First author: Zhejiang Academy of Agricultural Sciences, Hangzhou 310021, People's Republic of China; second, third, fourth, and sixth authors: Department of Virology, Scottish Crop Research Institute, Invergowrie, Dundee DD2 5DA, United Kingdom; and fifth author: Department of Molecular Biology, Vanderbilt University, Nashville, TN 37235.

Accepted for publication 9 December 1996.

\begin{abstract}
Chen, J., Torrance, L., Cowan, G. H., MacFarlane, S. A., Stubbs, G., and Wilson, T. M. A. 1997. Monoclonal antibodies detect a single amino acid difference between the coat proteins of soilborne wheat mosaic virus isolates: Implications for virus structure. Phytopathology 87:295-301.

Four monoclonal antibodies (MAbs) were prepared against an isolate of soilborne wheat mosaic furovirus from Oklahoma (SBWMV Okl-7). Three MAbs had different reactivities in tests on SBWMV isolates from Nebraska (Lab1), France, and Japan. One MAb (SCR 133) also reacted with oat golden stripe furovirus. None of the MAbs cross-reacted with other rod-shaped viruses including beet necrotic yellow vein furovirus, potato mop-top furovirus, and tobacco rattle tobravirus. Sequence analysis of nucleotides between 334 and 1,000 of RNA 2, the region that encodes the coat protein $(\mathrm{CP})$ and the first 44 amino acids of a readthrough

one to three amino acids in residues located near either the $\mathrm{N}$ - or $\mathrm{C}$-terminus of the CPs of the different isolates. Two further single amino acid changes were found at the beginning of the readthrough domain of the CP-readthrough protein. Some of these amino acid changes could be discriminated by MAbs SCR 132, SCR 133, and SCR 134. Peptide scanning (Pepscan) analysis indicated that the epitope recognized by SCR 134 is located near the N-terminus of the CP. SCR 132 was deduced to react with a discontinuous CP epitope near the C-terminus, and SCR 133 reacted with a surface-located continuous epitope also near the Cterminus. Predictions of CP structure from computer-assisted three-dimensional model building, by comparison with the X-ray fiber diffraction structure of tobacco mosaic virus, suggested that the three $\mathrm{CP}$ amino acids found to differ between isolates of SBWMV were located near the viral surface and were in regions predicted to be antigenic.
\end{abstract} protein, of the four SBWMV isolates revealed up to 27 base changes from the published sequence of a Nebraska field isolate of SBWMV. Most changes were translationally silent, but some caused differences of
Additional keywords: coat protein sequence, ELISA, epitope mapping.
Soilborne wheat mosaic furovirus (SBWMV) is a damaging soilborne virus that afflicts wheat in many countries including the United States, continental Europe, China, Japan, and Brazil (4). SBWMV does not occur in the United Kingdom, but a serologically related virus, oat golden stripe virus (OGSV), has been found in winter oats in England and Wales (1).

Previous work has shown that monoclonal antibodies (MAbs) prepared to a SBWMV isolate from Oklahoma detected isolates from four different states in the United States (3). Differences in the degree of reactivity of two of the MAbs (5A24 and 5A1) with a SBWMV isolate from Illinois were observed and attributed to degradation of antigen during transport between donor and testing laboratories.

This paper describes the production of MAbs that distinguish between geographically separate isolates of SBWMV. The results indicate that the MAbs detect changes in amino acids near the $\mathrm{N}$ and C-termini of the coat protein $(\mathrm{CP})$, which are predicted to be exposed on the outer surface of the virus. A minimum energy model for the three-dimensional structure of SBWMV CP is presented based on computer-assisted comparisons with the known structure of tobacco mosaic virus (TMV) CP $(2,17)$, the only helical, rod-shaped virus so far examined successfully by X-ray fiber diffraction (17).

Corresponding author: T. M. A. Wilson; E-mail address: m.wilson@scri.sari.ac.uk

Publication no. P-1997-0203-01R

(C) 1997 The American Phytopathological Society

\section{MATERIALS AND METHODS}

Virus isolates, maintenance, and purification. Two SBWMV isolates from the United States were used for antiserum production and RNA sequencing. The SBWMV Okl-7 isolate, a stable RNA 2-deletion mutant, was obtained by serial mechanical inoculation (7-9) of a field isolate of SBWMV from Oklahoma (OklWT), which was kindly provided by J. L. Sherwood (Oklahoma State University, Stillwater).

The SBWMV Lab1 isolate, another RNA 2-deletion mutant derived by successive manual inoculations of a Nebraska field isolate over 2 years (22), was generously provided by Y. Shirako (University of Tokyo). Both isolates were maintained by mechanical inoculation to wheat (Triticum aestivum) cv. Galahad (7). SBWMV was purified from infected wheat leaves by the method of Shirako and Brakke (21).

Two further SBWMV isolates and four other rod-shaped viruses (donors in parentheses) were used in MAb cross-reactivity tests: SBWMV from Japan (SBWMV-J; I. M. Roberts, Scottish Crop Research Institute [SCRI], Dundee, United Kingdom), France (SBWMV-F; M. J. Adams, Institute of Arable Crops Research, Rothamsted, Harpenden, United Kingdom), OGSV (M. J. Adams), potato mop-top virus (PMTV, isolate T [27]), beet necrotic yellow vein virus (BNYVV, strain H3; R. Koenig, Braunschweig, Germany), and tobacco rattle virus (TRV, strain PRN; D. J. Robinson, SCRI).

Polyclonal antiserum production. An antiserum to SBWMV Okl-7 was produced in a New Zealand white rabbit as follows: approximately $50 \mu \mathrm{g}$ of purified virions emulsified in complete 
Freund's adjuvant (CFA) were injected intramuscularly (half deposited in each leg) on day $1 ; 50 \mu \mathrm{g}$ of virions in incomplete Freund's adjuvant (IFA) were injected intramuscularly on day 14; and $100 \mu \mathrm{g}$ of virions were injected subcutaneously on day 126 . Antiserum was collected 2 weeks after the final injection. The titer was $1 / 128$ in microprecipitin tests against purified preparations of SBWMV Okl-7.

Hybridoma production, screening, and isotyping. The MAbsecreting cell lines were derived from fusions between spleen cells from immunized BALB/c mice (taken 3 days after the last injection) and the mouse myeloma cell line X63/Ag 8.653. Immunization schedules were as follows: fusion 1 (20 to $50 \mu \mathrm{g}$ of SBWMV Okl-7 virions per injection) on day 1, intraperitoneal in CFA; day 28, intraperitoneal in IFA; day 107, intraperitoneal in IFA; and day 321, intravenous in phosphate-buffered saline (PBS); and fusion 2 (25 $\mu \mathrm{g}$ of SBWMV Okl-7 virions per injection) on day 1 , subcutaneously in IFA; day 14, subcutaneously in IFA; and day 126, intravenous in PBS. The procedures for cell fusion, cloning by limiting dilution, and maintenance of hybridomas are described by Torrance (25). About 10 days after fusion, hybridomas were screened for specific antibody production by enzymelinked immunosorbent assay (ELISA) (see below).

ELISA. ELISAs were done essentially as described by Chen et al. (9). In antibody-trapped antigen (ATA)-ELISA (24), plant sap and conjugate were diluted in PBS containing $0.1 \%$ ( $\mathrm{vol} / \mathrm{vol}$ ) Tween-20 (PBS-T) and 0.1\% (wt/vol) nonfat milk powder. Rabbit antiserum to SBWMV Okl-7 was used at a dilution of 1:1,000 for $2 \mathrm{~h}$ at $37^{\circ} \mathrm{C}$. Sap extracts of wheat infected with SBWMV Okl-7 or SBWMV Lab1 were used at a dilution of 1:10 and incubated at $4{ }^{\circ} \mathrm{C}$ overnight. The undiluted culture supernatant fluids were incubated at room temperature for $2 \mathrm{~h}$ and detected by the addition of alkaline phosphatase-conjugated goat anti-mouse IgG (Sigma Chemical Co., St. Louis).

Electron microscopy showed that SBWMV particles were disrupted in $0.05 \mathrm{M}$ sodium carbonate-bicarbonate, $\mathrm{pH} 10.5$ (coating buffer; J. Chen, unpublished data), and this buffer was used to prepare sap extracts for plate-trapped antigen (PTA)-ELISA (4, 25). Therefore, PTA-ELISA was used to select MAbs that might be specific for cryptotopes. Sap extracts from SBWMV Okl-7infected leaves $(1 \mathrm{~g} / 10 \mathrm{ml})$ were made in coating buffer and incubated at $4{ }^{\circ} \mathrm{C}$ overnight in the wells of microtiter plates. After the removal of sap by rinsing the plates with PBS-T, the plates were blocked with $0.5 \%(\mathrm{wt} / \mathrm{vol})$ nonfat milk powder in PBS-T for $1 \mathrm{~h}$ at room temperature. The procedures for antibody, enzyme conjugate, and substrate incubations were the same as for ATA-ELISA.

Other SBWMV isolates and rod-shaped viruses were tested for reactivity by ATA-ELISA using homologous rabbit polyclonal antiserum to trap each virus to microtiter plates, and using each of the anti-SBWMV Okl-7 MAbs as the second antibody. Homologous MAbs to PMTV, BNYVV, or TRV were included as positive controls with the other rod-shaped viruses. Noninfected plant sap extracts were used as negative controls. Absorbance values greater than twice the appropriate negative control were considered positive.

Isotype tests were done using a mouse monoclonal antibody isotyping kit (ISO-2; Sigma Immuno-Chemicals, St. Louis) following the manufacturer's instructions.

Trypsin-treatment, sodium dodecyl sulfate-polyacrylamide gel electrophoresis (SDS-PAGE), and immunoblotting. Thirty micrograms of purified SBWMV Okl-7 virions was incubated

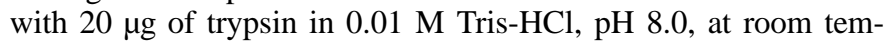
perature for 5, 20, or $60 \mathrm{~min}$. The samples were then mixed with gel-loading buffer (0.06 M Tris-HCl, pH 6.8, containing 20 g/liter of SDS, $5 \mathrm{ml} /$ liter of $\beta$-mercaptoethanol, $1 \mathrm{ml} / \mathrm{liter}$ of glycerol, and $0.2 \mathrm{~g} /$ liter of bromophenol blue) for SDS-PAGE (16) and immunoblotting (28).

Sap extracts from SBWMV Okl-7- or SBWMV Lab1-infected wheat leaves $(0.2 \mathrm{~g})$ were made in $2 \mathrm{ml}$ of $0.01 \mathrm{M}$ Tris- $\mathrm{HCl}, \mathrm{pH}$ 8.0 , and treated with $20 \mu \mathrm{g}$ of trypsin for $60 \mathrm{~min}$ at room temperature before electron microscopy.

Electron microscopy. The methods for immunosorbent electron microscopy and antibody coating were as described by Roberts et al. (19).

Molecular biology. The methods for RNA extraction, reverse transcriptase-polymerase chain reaction (RT-PCR), cDNA cloning, and sequencing were those described by Chen et al. (7,9). A 738-nucleotide region extending from RNA 2 genome coordinates 300 to 1,037 and including the entire CP gene was amplified from first-strand cDNA of SBWMV isolates Okl-7, Lab1, and -F using primers JC28 (5'-ATTATTGCCAAAGGTTA-3') and JC41 (5'ATGATAGACAGAACTTT-3') (23). The fragments were inserted into pT7Blue PCR-cloning vector (Novagen, Inc., Madison, WI) and sequenced using a kit (Amersham International, Amersham, United Kingdom) according to the manufacturer's instructions. Sequence analysis was carried out using the Genetics Computer Group programs (11). The EMBL sequence accession number for SBWMV-F is X89078.

Peptide scanning (Pepscan). A set of overlapping octapeptides was synthesized on cellulose paper using a SPOTs kit (Genosys Biotechnologies Inc., Cambridge) and tested for reaction with MAbs by the methods described by Pereira et al. (18). Seven spots contained amino acids in the sequence 1-MAVNKGYTGYNKEL from the N-terminus of SBWMV Okl-7 CP. A positive control spot of sequence STVVVKGN, the epitope for MAb SCR 3 (26), was also included.

TABLE 1. Some properties of monoclonal antibodies against soilborne wheat mosaic virus (SBWMV)

\begin{tabular}{|c|c|c|c|c|c|c|c|c|c|c|}
\hline \multirow[b]{2}{*}{ Code name } & \multirow[b]{2}{*}{ Isotype } & \multirow[b]{2}{*}{$\begin{array}{c}\text { Titer } \\
\text { ATA-ELISA }\end{array}$} & \multicolumn{3}{|c|}{ ATA-ELISA $^{a}$} & \multicolumn{3}{|c|}{ PTA-ELISA $^{\mathrm{b}}$} & \multicolumn{2}{|c|}{ Immunoblot $^{\mathrm{c}}$} \\
\hline & & & $\begin{array}{l}\text { SBWMV } \\
\text { Okl-7 }\end{array}$ & $\begin{array}{c}\text { SBWMV } \\
\text { Lab1 }\end{array}$ & $\mathrm{H}^{\mathrm{d}}$ & $\begin{array}{l}\text { SBWMV } \\
\text { Okl-7 }\end{array}$ & $\begin{array}{l}\text { SBWMV } \\
\text { Lab1 }\end{array}$ & $\mathrm{H}$ & $\begin{array}{c}\text { SBWMV } \\
\text { Okl-7 }\end{array}$ & $\begin{array}{c}\text { SBWMV } \\
\text { Lab1 }\end{array}$ \\
\hline \multicolumn{11}{|l|}{ Cloned lines } \\
\hline SCR 132 & $\operatorname{IgG}_{2 b}$ & $262,144^{\mathrm{e}}$ & $1.921^{\mathrm{f}}$ & 1.831 & 0.067 & 0.844 & 0.680 & 0.032 & - & - \\
\hline SCR 133 & $\mathrm{IgG}_{3}$ & 4,096 & 1.851 & 0.271 & 0.038 & 0.267 & 0.139 & 0.046 & +++ & + \\
\hline SCR 134 & $\mathrm{IgG}_{2 \mathrm{~b}}$ & 64 & 1.830 & 0.063 & 0.046 & 0.515 & 0.039 & 0.023 & + & - \\
\hline SCR 135 & $\mathrm{IgG}_{3}$ & 256 & 0.770 & 0.568 & 0.071 & 0.322 & 0.279 & 0.100 & +++ & +++ \\
\hline \multicolumn{11}{|c|}{ Uncloned lines } \\
\hline $2 / 4$ & $\operatorname{IgM}$ & 256 & 1.944 & 0.099 & 0.034 & 0.469 & 0.080 & 0.034 & - & - \\
\hline $2 / 6 \mathrm{D} 9$ & $\operatorname{IgG}_{2 \mathrm{a}}$ & 256 & 0.371 & 0.030 & 0.023 & 0.037 & 0.037 & 0.038 & + & - \\
\hline $2 / 6 \mathrm{D} 7$ & $\operatorname{IgG}_{2 \mathrm{a}}$ & 64 & 0.271 & 0.036 & 0.028 & 0.031 & 0.035 & 0.036 & + & - \\
\hline
\end{tabular}

a ATA-ELISA = antibody-trapped antigen-enzyme-linked immunosorbent assay.

b PTA-ELISA = plate-trapped antigen-enzyme-linked immunosorbent assay.

c $+++=$ strongly stained band; $+=$ weak reaction; and $-=$ no reaction.

${ }^{\mathrm{d}} \mathrm{H}=$ healthy plant sample.

e Reciprocal of greatest dilution of culture supernatant fluid that reacted with SBWMV Okl-7.

f Absorbance value $\left(\mathrm{A}_{405 \mathrm{~nm}}\right)$ after $1 \mathrm{~h}$ of substrate incubation. 


\section{RESULTS}

Characterization of MAbs. MAbs SCR 135 and SCR 133 were selected from the first fusion and MAbs SCR 132 and SCR 134 were selected from the second fusion. Several other hybridoma lines were obtained from the second fusion that were unstable and stopped secreting antibodies after cloning, e.g., cell lines 2/4, 2/6D9, and 2/6D7. Some properties of the cell lines are given in Table 1.

All seven antibody preparations reacted with the homologous antigen SBWMV Okl-7 in ATA-ELISA, whereas only SCR 132,

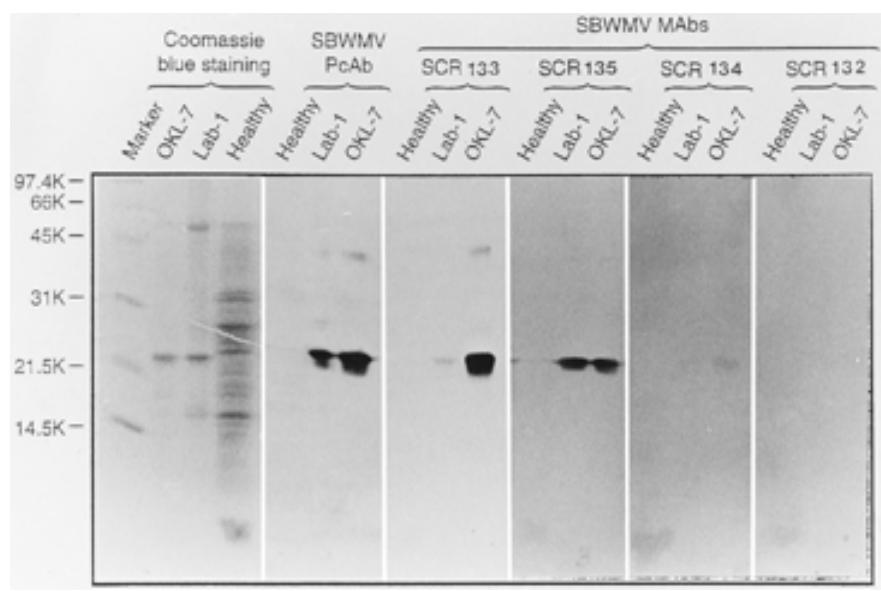

Fig. 1. Sodium dodecyl sulfate-polyacrylamide gel electrophoresis and immunoblots of healthy wheat leaf sap and purified preparations of soilborne wheat mosaic furovirus (SBWMV) isolates Okl-7 and Lab1. Immunoblots were probed with polyclonal rabbit antiserum $(\mathrm{PcAb})$ or monoclonal antibodies (MAbs) SCR 133, SCR 135, SCR 134, or SCR 132 against SBWMV. Protein size markers are shown on the left $(K=\mathrm{kDa})$.

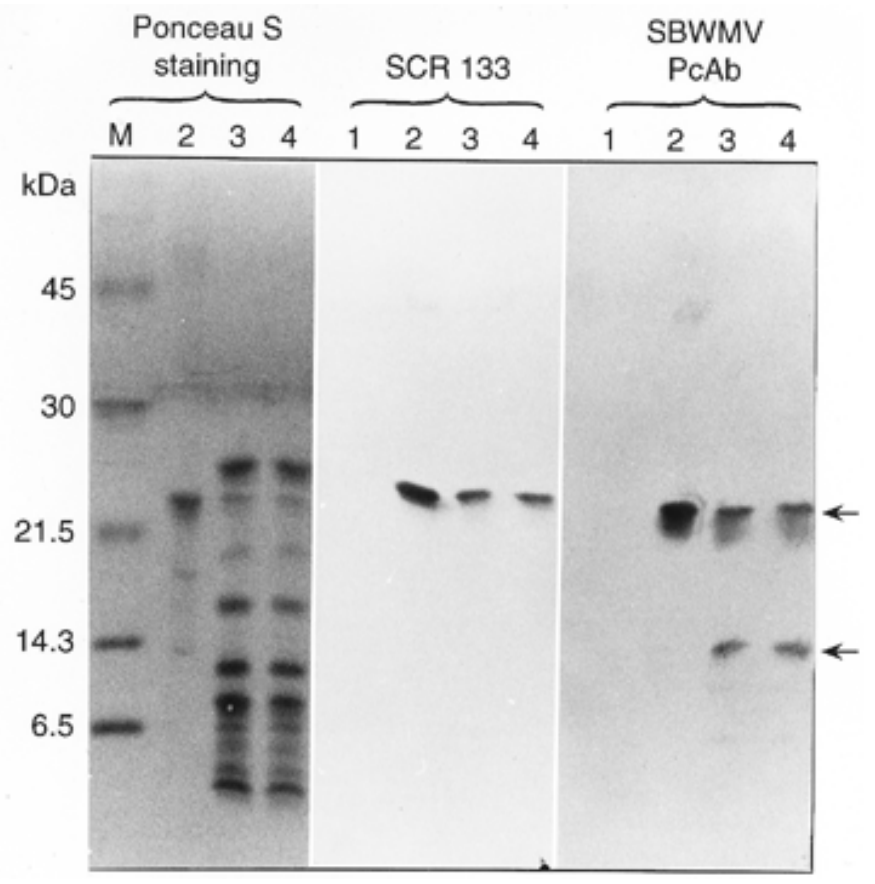

Fig. 2. Sodium dodecyl sulfate-polyacrylamide gel electrophoresis of purified soilborne wheat mosaic furovirus (SBWMV) Okl-7 particles with or without trypsin treatment. Gels were stained (Ponceau S) or immunoblotted with monoclonal antibody SCR 133 or rabbit polyclonal antibody (PcAb). Healthy wheat sap is shown in lanes 1 . Particles were untreated (lanes 2) or treated with trypsin for 5 or 20 min (lanes 3 and 4, respectively). Right arrows indicate the immunoreactive bands. Marker protein (lane M) sizes are given on the left.
SCR 133 (weak), and SCR 135 reacted with SBWMV Lab1 (Table 1). A similar result was obtained in PTA-ELISA in which SCR 132, SCR 133, and SCR 135 reacted with both SBWMV Okl-7 and SBWMV Lab1, but SCR 134 and 2/4 reacted strongly only with SBWMV Okl-7. The two other uncloned lines did not work in PTA-ELISA (Table 1). Therefore, antibodies secreted by five out of the seven hybridoma lines obtained discriminated between the two American SBWMV isolates in ATA-ELISA.

In immunoblot experiments, the rabbit polyclonal antiserum reacted strongly with the $\mathrm{CP}$ and weakly with an approximately 40$\mathrm{kDa}$ band (possibly a dimer of CP) in preparations from SBWMV Okl-7 and SBWMV Lab1 (Fig. 1). Of the seven MAb preparations, only SCR 135 reacted strongly in immunoblots with the $\mathrm{CP}$ of both isolates (Table 1 and Fig. 1). SCR 133 reacted strongly with SBWMV Okl-7 and weakly with SBWMV Lab1, and SCR 134 reacted very weakly with SBWMV Okl-7, but not with SBWMV Lab1. SCR 132 did not react in this test.

Trypsin-treatment of SBWMV particles. Electron microscopy of purified particles of SBWMV Okl-7 after trypsin treatment for 60 min showed that the particles were intact with no evidence of disruption or degradation. However, SDS-PAGE, Ponceau S staining, and immunoblotting of trypsin-treated (5 and $20 \mathrm{~min}$ ) virus showed that, in addition to intact $\mathrm{CP}$ (19 $\mathrm{kDa}$ by sequence [23], but of apparent gel mobility of approximately 22

TABLE 2. Comparison of the effects of trypsin-treatment of soilborne wheat mosaic furovirus (SBWMV) particles on electron microscopy trapping and coating reactions obtained with monoclonal antibodies SCR 132 and SCR 133

\begin{tabular}{|c|c|c|c|c|c|}
\hline \multirow[b]{3}{*}{ Antibody } & \multirow[b]{3}{*}{ Experiment } & \multicolumn{4}{|c|}{ SBWMV isolate } \\
\hline & & \multicolumn{2}{|c|}{ Okl-7 } & \multicolumn{2}{|c|}{ Lab1 } \\
\hline & & Trypsin $^{a}$ & $\mathrm{U}^{\mathrm{a}}$ & Trypsin & $\mathrm{U}$ \\
\hline \multirow[t]{2}{*}{$\mathrm{PcAb}^{\mathrm{b}}$} & Trapping & $514^{c}$ & 707 & 2,718 & 5,341 \\
\hline & Coating $\mathrm{d}$ & $+^{e}$ & + & + & + \\
\hline \multirow[t]{2}{*}{ SCR 132} & Trapping & 133 & 465 & 15 & 391 \\
\hline & Coating & + & + & + & + \\
\hline \multirow[t]{2}{*}{ SCR 133} & Trapping & 0 & 22 & 13 & 15 \\
\hline & Coating & - & + & - & - \\
\hline \multirow[t]{2}{*}{ Normal serum } & Trapping & 0 & 0 & 9 & 17 \\
\hline & Coating & - & - & - & - \\
\hline
\end{tabular}

a Trypsin $=$ trypsin-treated $(60 \mathrm{~min})$ and $\mathrm{U}=$ untreated.

${ }^{b}$ SBWMV rabbit polyclonal antiserum.

${ }^{\mathrm{c}}$ Number of particles in $4.5 \times 10^{-10} \mathrm{~m}^{2}$.

${ }^{\mathrm{d}}$ For coating experiments, virions were first trapped using polyclonal antibody.

$\mathrm{e}^{\mathrm{e}}=+$ Uniform coating along the sides of particles and $-=$ no antibody coat ing.
A

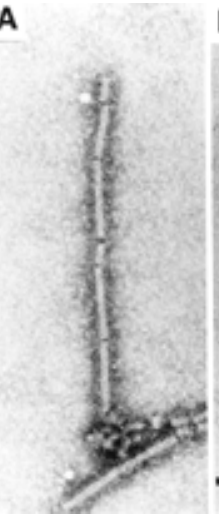

B

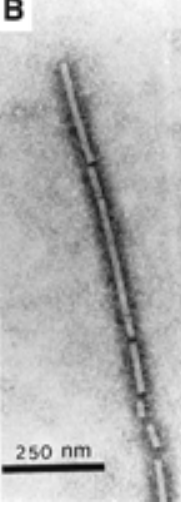

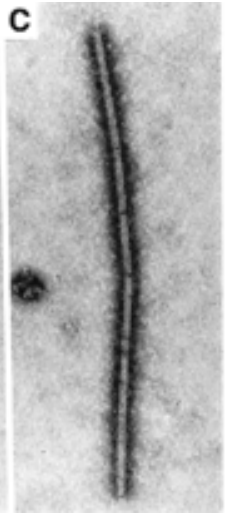

D

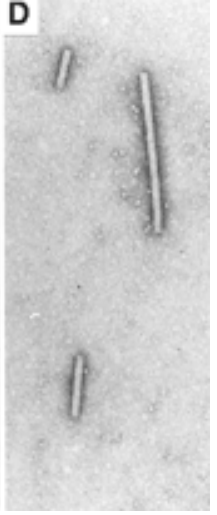

Fig. 3. Electron micrographs of soilborne wheat mosaic furovirus (SBWMV) Okl-7 particles coated with A, rabbit polyclonal antiserum; B, monoclonal antibody (MAb) SCR 132; C, MAb SCR 133; or D, untreated control particles. Virions were first trapped using polyclonal antibody. Scale bar $=250$ $\mathrm{nm}$ 
$\mathrm{kDa}$ ), several polypeptide fragments were produced (Fig. 2). Two bands (CP and a 13-kDa species) reacted with rabbit polyclonal antiserum to SBWMV. MAb SCR 133 reacted only with the $\mathrm{CP}$ band and not with the smaller fragment. Therefore, the epitope with which SCR 133 reacts is probably located within $6 \mathrm{kDa}$ (19 $\mathrm{kDa}$ minus $13 \mathrm{kDa}$ ) of one extremity of the linear $\mathrm{CP}$ sequence.

Immunosorbent electron microscopy trapping and coating tests (Table 2 and Fig. 3) of untreated or 60 min-trypsin-treated SBWMV Okl-7- or SBWMV Lab1-infected sap showed that the rabbit polyclonal antiserum trapped and coated both untreated and trypsin-treated virus particles of both isolates. SCR 132 also trapped and coated untreated particles of both isolates, but many

TABLE 3. Cross-reactions of monoclonal antibodies (MAbs) with four isolates of soilborne wheat mosaic furovirus (SBWMV) and other rod-shaped viruses $^{\mathrm{a}}$

\begin{tabular}{lcccc}
\hline & \multicolumn{4}{c}{ MAb } \\
\cline { 2 - 5 } & SCR 132 & SCR 133 & SCR 134 & SCR 135 \\
\hline SBWMV Ok1-7 & $1.964^{\mathrm{b}}$ & 2.059 & 1.048 & 0.443 \\
SBWMV Lab1 & 1.589 & 0.443 & 0.193 & 0.540 \\
SBWMV-F & 0.134 & 1.165 & 0.187 & 0.195 \\
SBWMV-J & 0.511 & 0.904 & 0.165 & 0.157 \\
Healthy wheat & 0.151 & 0.146 & 0.142 & 0.147 \\
OGSV & 0.209 & 1.108 & 0.133 & 0.137 \\
Healthy oat & 0.140 & 0.127 & 0.157 & 0.147 \\
PMTV & 0.073 & 0.075 & 0.070 & 0.085 \\
Healthy potato & 0.063 & 0.078 & 0.070 & 0.066 \\
BNYVV & 0.069 & 0.062 & 0.106 & 0.065 \\
Healthy sugar beet & 0.069 & 0.060 & 0.116 & 0.082 \\
TRV-PRN & 0.062 & 0.058 & 0.064 & 0.058 \\
Healthy tobacco & 0.066 & 0.061 & 0.059 & 0.065 \\
\hline
\end{tabular}

${ }^{\mathrm{a}}$ OGSV $=$ oat golden stripe virus, PMTV = potato mop-top virus, BNYVV = beet necrotic yellow vein virus, and TRV-PRN = tobacco rattle virus strain PRN.

${ }^{\mathrm{b}} \mathrm{A}_{405 \mathrm{~nm}}$ value in antibody-trapped antigen-enzyme-linked immunosorbent assay using homologous antibody preparations to coat microtiter plates. Value recorded after $1 \mathrm{~h}$ of substrate incubation.

TABLE 4. Nucleotide differences between soilborne wheat mosaic furovirus (SBWMV) RNA 2 isolates between nucleotides 334 and 1,000

\begin{tabular}{|c|c|c|c|c|}
\hline Base & Okl-WT & Okl-7 & Lab-1 & $-F$ \\
\hline 349 & G & G & $\mathrm{A}^{* \mathrm{a}}$ & $\mathrm{A}^{*}$ \\
\hline 408 & C & C & $\mathrm{T}$ & $\mathrm{T}$ \\
\hline 471 & $\mathrm{~T}$ & $\mathrm{~T}$ & $\mathrm{C}$ & $\mathrm{C}$ \\
\hline 474 & G & G & A & A \\
\hline 546 & A & G & G & G \\
\hline 552 & C & $\mathrm{T}$ & $\mathrm{T}$ & $\mathrm{T}$ \\
\hline 582 & G & G & A & A \\
\hline 600 & G & $\mathrm{G}$ & G & $\mathrm{C}$ \\
\hline 601 & C & C & C & $\mathrm{G}^{*}$ \\
\hline 624 & $\mathrm{~T}$ & $\mathrm{C}$ & $\mathrm{T}$ & $\mathrm{T}$ \\
\hline 633 & $\mathrm{G}$ & A & A & A \\
\hline 639 & $\mathrm{~T}$ & $\mathrm{~T}$ & C & $\mathrm{T}$ \\
\hline 651 & C & C & $\mathrm{T}$ & $\mathrm{T}$ \\
\hline $663^{b}$ & G & $\mathrm{G}$ & G & $\mathrm{G}$ \\
\hline 669 & C & $\mathrm{C}$ & $\mathrm{T}$ & $\mathrm{T}$ \\
\hline 729 & $\mathrm{~T}$ & C & $\mathrm{T}$ & $\mathrm{T}$ \\
\hline 735 & $\mathrm{C}$ & $\mathrm{C}$ & $\mathrm{T}$ & $\mathrm{T}$ \\
\hline 765 & G & G & A & A \\
\hline 783 & $\mathrm{~T}$ & G & G & G \\
\hline 792 & C & C & $\mathrm{T}$ & $\mathrm{T}$ \\
\hline 808 & $\mathrm{~T}$ & $\mathrm{~T}$ & $\mathrm{~T}$ & $\mathrm{~A}^{*}$ \\
\hline 809 & A & A & A & $\mathrm{T}^{*}$ \\
\hline 810 & $\mathrm{~T}$ & $\mathrm{~T}$ & $\mathrm{~T}$ & $\mathrm{~A}^{*}$ \\
\hline 811 & A & A & A & $\mathrm{T}^{*}$ \\
\hline 872 & G & G & $\mathrm{A}^{*}$ & G \\
\hline 948 & C & C & $\mathrm{T}$ & $\mathrm{T}$ \\
\hline 997 & G & G & $\mathrm{A}^{*}$ & $\mathrm{~A}^{*}$ \\
\hline
\end{tabular}

a $*$ = Nucleotide caused amino acid changes in coat protein or coat proteinreadthrough protein when compared with SBWMV Okl-WT and SBWMV Okl-7.

${ }^{\mathrm{b}}$ Base 663 is an A in Nebraska WT strain RNA2. fewer untreated SBWMV Lab1 particles were trapped by SCR 132 than by the rabbit polyclonal antiserum. SCR 132 also trapped fewer trypsin-treated particles of SBWMV Okl-7, but only a very small number of trypsin-treated particles of SBWMV Lab1. However, SCR 132 coated both treated and untreated particles of both isolates. SCR 133 failed to trap appreciable numbers of any SBWMV particles and only coated untreated SBWMV Okl-7 particles.

Tests for cross-reactivity with other SBWMV isolates and rod-shaped viruses. SBWMV-J, SBWMV-F, OGSV, PMTV, BNYVV, and TRV-PRN were tested by ATA-ELISA. The viruses were trapped using homologous polyclonal antisera and detected with homologous MAbs (positive controls) (data not shown) or with each of the four SBWMV MAbs.

The results of a typical experiment are presented in Table 3 and show that only SCR 133 reacted with all four SBWMV isolates, although consistently weaker with Lab1 compared with the others (Table 1). SCR 133 reacted strongly with OGSV. SCR 132 reacted with SBWMV Okl-7, SBWMV Lab1, and SBWMV-J (weakly), but not with SBWMV-F or OGSV. SCR 135 reacted weakly with SBWMV Okl-7 and SBWMV Lab1, but not with SBWMV-F, SBWMV-J, or OGSV. SCR 135 reacted in immunoblots with SDS-denatured CP, and so probably detects a continuous epitope. However, no further tests were done with this MAb, because the cells stopped producing antibodies and the cell line could not be recovered. SCR 134 reacted only with SBWMV Okl-7. None of the MAbs reacted with PMTV, BNYVV, or TRV-PRN.

Sequence analysis of the $C P$ and part of the readthrough domain of SBWMV isolates. RT-PCR cloning and sequencing of nucleotides 334 to 1,000 of SBWMV Okl-7, SBWMV Lab1, and
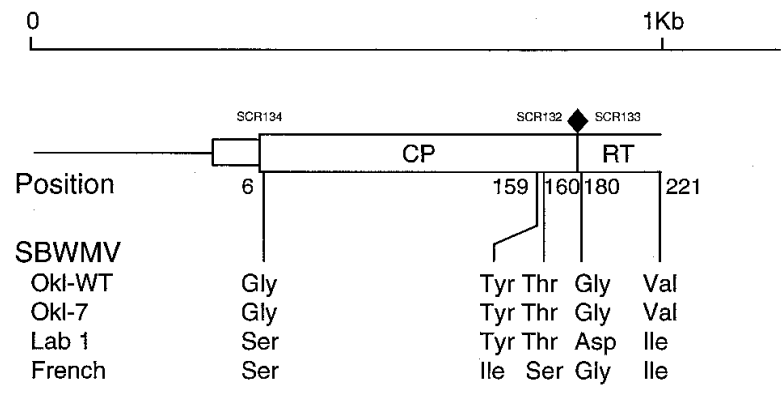

Translation terminal stop codon.

Fig. 4. Diagram of the coat protein $(\mathrm{CP})$ and $\mathrm{N}$-terminal part of the $\mathrm{CP}$ readthrough domain of soilborne wheat mosaic virus showing the positions of the amino acid changes between the sequences of the four isolates studied and the predicted locations of monoclonal antibody binding.

TMV

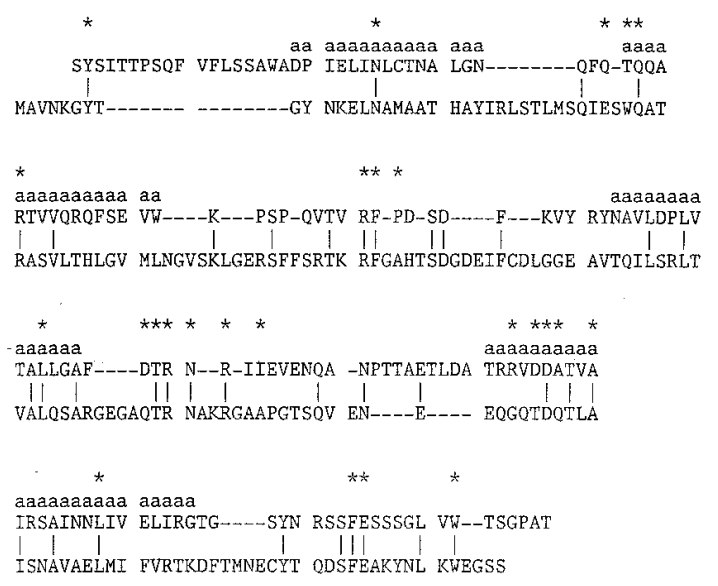

Fig. 5. Amino acid sequence alignment of the coat proteins (CPs) of tobacco mosaic virus (TMV) and soilborne wheat mosaic furovirus (SBWMV). Residues marked "a" are in alpha-helices in TMV. Residues marked "*” are conserved in all tobamoviruses. 
SBWMV-F RNA 2, which encode the CP and the first 44 amino acids of the CP-readthrough domain (CP-RT) showed that they differed from SBWMV Okl-WT at up to 27 loci (Table 4). However, most nucleotide changes did not alter the amino acid sequences of the proteins. The deduced amino acid sequences of the SBWMV Okl-7 CP and CP-RT domains were the same as those of SBWMV Okl-WT (7), but the SBWMV Lab1 and SBWMV-F CPs differed from SBWMV Okl-WT by one or three amino acids, respectively (Fig. 4). The CPs of SBWMV Lab1 and SBWMV-F both differed from SBWMV Okl-WT by one amino acid near the $\mathrm{N}$-terminus (Gly to Ser at position 6). The SBWMV-F CP also differed from SBWMV Okl-WT towards the C-terminus (Tyr-159 and Thr-160 were changed to Ile and Ser, respectively; Fig. 4).

Analysis showed that Gly-180 (in the N-terminal part of the readthrough domain of the CP-RT protein) was conserved in all isolates except SBWMV Lab1, where it was changed to Asp-180. SBWMV Lab1 and SBWMV-F also differed from SBWMV OklWT in the CP-RT domain, where Val-221 was changed to Ile-221.

Pepscan. Pepscan analysis has been used successfully to identify continuous epitopes on BNYVV and PMTV CPs $(10,18)$. SCR 133 and SCR 134 probably react with continuous epitopes, because they reacted with SDS-denatured $\mathrm{CP}$ in immunoblots (Fig. 1), although the reaction with SCR 134 was weak.

A set of seven overlapping octapeptides corresponding to amino acids at the N-terminus of the SBWMV Okl-WT CP (1MAVNKGYTGYNKEL) were synthesized on cellulose paper as described (18). In subsequent tests, SCR 134 reacted only with spot 3-VNKGYTGY, and SCR 133 did not react with any of the spots (data not shown).

Computer-assisted model building. A three-dimensional structural model of SBWMV CP was constructed by considering the amino acid sequence similarity with TMV CP and the known structure of TMV CP $(15,17)$. TMV CP was chosen as template, because of the sequence similarity between the two proteins and because of their functional and geometric similarities. Alignments of the CPs of several rod-shaped viruses has shown that key amino acid residues identified as having important structural roles are conserved among them (12). Model building based on amino acid sequence similarity is a well-established procedure (5). Although the $25 \%$ similarity between SBWMV and TMV CPs is close to the lower limit appropriate for such modeling, it extends over a large number of amino acids and, together with other similarities between the two proteins, makes structural similarities highly probable (13). The sequences were aligned (Fig. 5) according to the requirements that the four core alpha-helices should not contain any insertions or deletions, and that, wherever possible, residues conserved in all tobamoviruses (2) should also be conserved in SBWMV.

A speculative model of the SBWMV CP molecule was constructed using the program Discover (Biosym Technologies, San Diego, CA). In general, large insertions were added as loops projecting from the protein surface, while small insertions and deletions were constructed by replacing one or two adjacent residues with the appropriate slightly larger or smaller sequence. The structure was frequently adjusted by repeated cycles of energy minimization, which removed the structural strains induced by the modifications. A ribbon drawing of the model is shown in Figure 6A, together with the TMV CP (Fig. 6B) for comparison.

\section{DISCUSSION}

Four MAbs produced against an isolate of SBWMV from Oklahoma (Okl-7) discriminated between SBWMV isolates of different geographic origin in ATA-ELISA. MAb SCR 133 reacted with all four SBWMV isolates (Okl-7, -J, -F, and Lab1) and OGSV. In contrast, SCR 134 reacted only with SBWMV Okl-7; SCR 135 reacted only with SBWMV Okl-7 and SBWMV Lab1; and SCR 132 reacted with SBWMV Okl-7, SBWMV Lab 1, and SBWMV-J. None of the MAbs reacted with PMTV, BNYVV, or TRV-PRN.

The complete nucleotide sequences of the RNA 2 of SBWMV isolates Okl-WT, Okl-7, and Nebraska-WT have been published
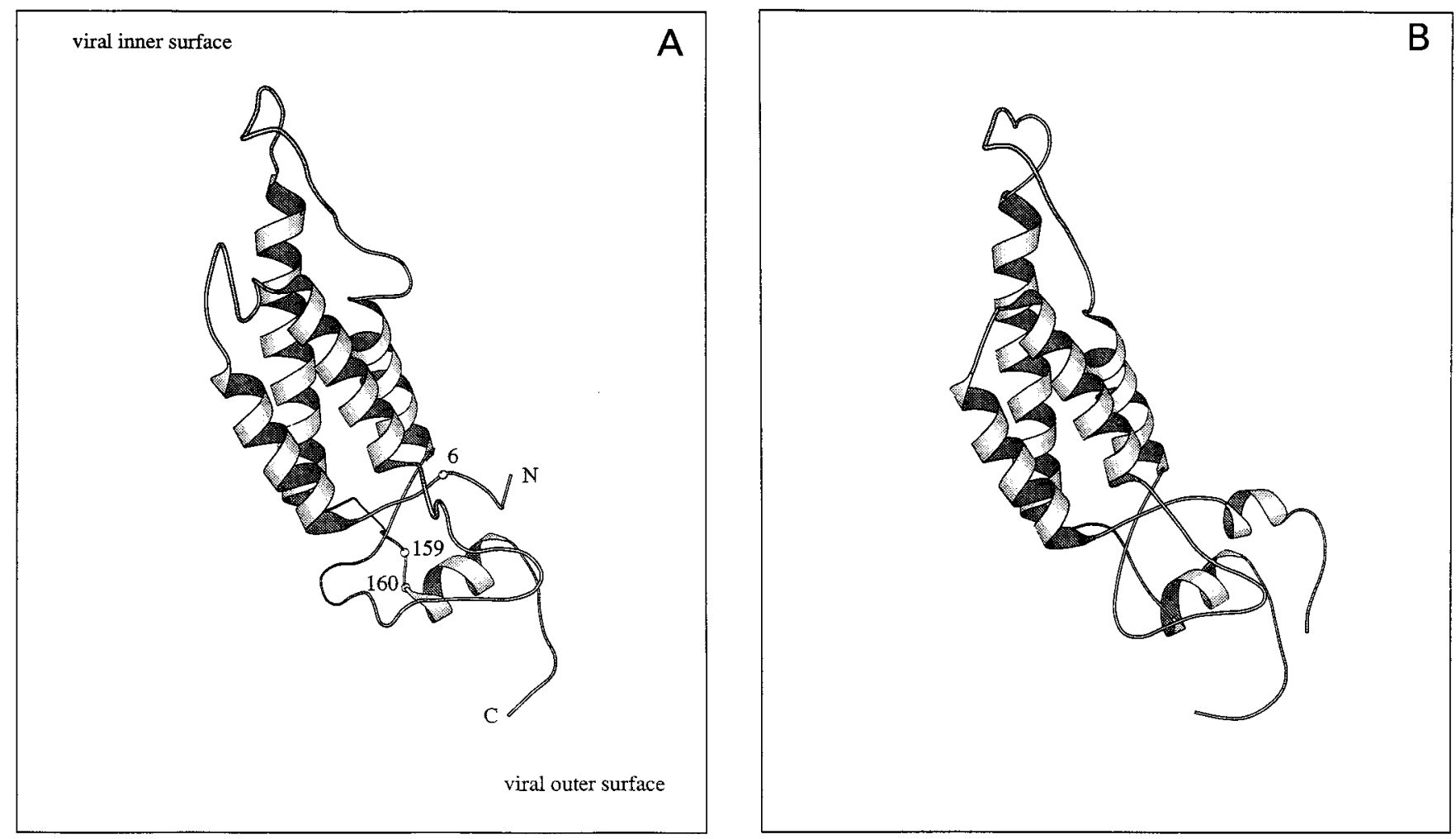

Fig. 6. Predicted three-dimensional structure for A, soilborne wheat mosaic furovirus (SBWMV) coat protein (CP) and B, tobacco mosaic virus (TMV) CP. The putative immunodominant site at amino acid position 6 is indicated. The positions of amino acid residues 159 and 160, which are altered in SBWMV-F and affect monoclonal antibody SCR 132 binding, are shown. Drawn using MOLSCRIPT (15). 
$(9,23)$. The deduced amino acid sequences of the CPs of these isolates are identical. Furthermore, the CP of SBWMV Lab1, a deletion mutant of the Nebraska isolate, was found to differ from these other isolates by only one amino acid (Ser for Gly) at position 6 from the N-terminus (20).

The RT-PCR cloning and sequencing work reported here confirms the Ser-6 for Gly-6 change in SBWMV Lab1 and identified the same change in SBWMV-F. SBWMV-F also contained two further changes located near the $\mathrm{C}$-terminus of the $\mathrm{CP}$. Predictions of the antigenic structure of the CP (Fig. 7) using the antigenic index algorithm of Jameson and Wolf (14), part of the Genetic Computer Group peptide structure programs (11), indicated that changes at amino acid positions 6, 159, and 160 would increase the antigenic index in these parts of the sequence.

The epitope with which SCR 132 reacts is probably discontinuous, because the MAb did not react with SDS-denatured CP. MAb SCR 132 was shown by electron microscopy to react at the surface and along the sides of virus particles. The epitope was not removed completely by treatment of particles with trypsin, but reactivity was diminished. SCR 132 reacted with three of the four isolates of SBWMV. It did not detect SBWMV-F, which differs from SBWMV Okl-7 and SBWMV Lab1 at amino acid positions 159 and 160. Thus, it is possible that the SCR 132 epitope contains the amino acids Tyr-159 and Thr-160.

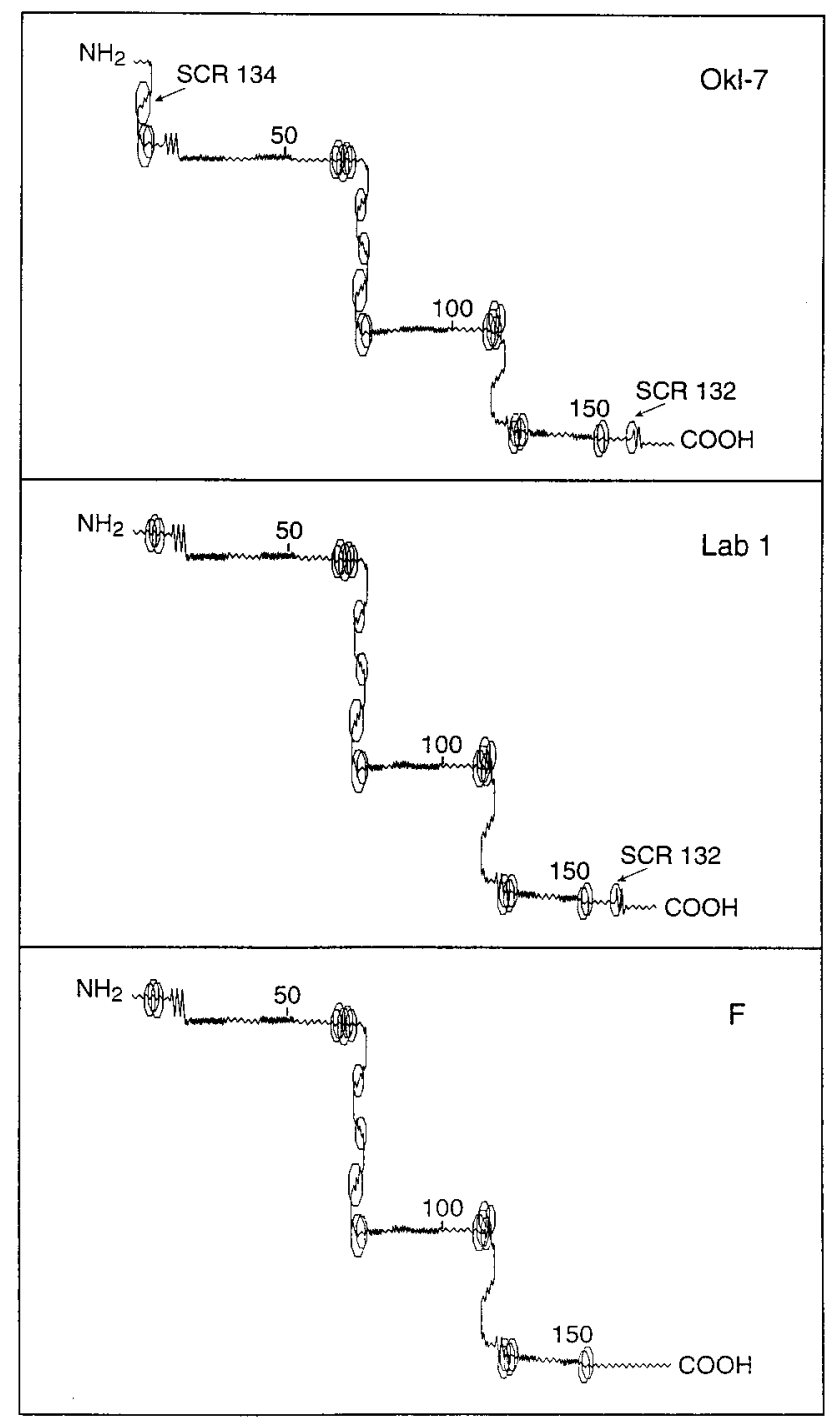

Fig. 7. Antigenic index plot of soilborne wheat mosaic furovirus (SBWMV) coat protein from isolates SBWMV Okl-7, SBWMV-F, and SBWMV Lab1. Putative epitopes for monoclonal antibodies SCR 134 and SCR 132 are shown.
From our results, we deduce that MAb SCR 133 reacts with a continuous epitope located at one end of the linear CP sequence. The epitope was exposed on the surface along the sides of the particles and was readily removed by trypsin-treatment. Since MAb SCR 133 reacted with all isolates, it seems unlikely that it discriminates the Ser-6 for Gly-6 change in SBWMV-F and SBWMV Lab1. It is, therefore, probable that it reacts with an epitope near the C-terminus, the amino acid residues of which are identical in SBWMV Lab1, SBWMV Okl-WT, and SBWMV Okl-7.

MAb SCR 134 reacted only with SBWMV Okl-7, and this can be explained by assuming that it reacts with an epitope that contains Gly-6 near the N-terminus of the CP. The Pepscan data support this conclusion.

The SBWMV CP amino acid sequence fitted easily into the TMV CP fold. The main modifications required were a 10-residue deletion near the $\mathrm{N}$-terminus, an eight amino acid deletion at TMV CP residue 101, and four- to eight-residue insertions at TMV CP amino acid positions 32, 52, 66, 87, and 137. The model-building strategy, thus, demonstrates the feasibility of the protein fold suggested, although it does not prove its existence. The general topology and the approximate positions of the amino acids are probably correct, although fine details such as specific side-chain interactions cannot be predicted by models based on similarities of less than $50 \%$ (13). During virus assembly, the sites of the N-terminal deletion and the insertions at 52, 66, and 137 would interact spatially, as would the sites of the deletion at 101 and the insertions at 32 and 87. Significantly, Gly-6, Tyr-159, and Thr-160 are all near the viral surface in the model and are probably exposed (Fig. 6A), so that any modifications to them could affect antibody binding.

The MAbs produced in this work confirm the serological relationship previously found between OGSV and SBWMV (6). They will be useful for surveys to verify the health status of winter wheat crops in the United Kingdom and elsewhere and in further basic research on SBWMV.

\section{ACKNOWLEDGMENTS}

We thank all those who provided virus isolates, M. Adams for wheat grain (cv. Galahad), I. Roberts for assistance with electron microscopy, and J. Antoniw for running the antigenic index shown in Figure 7. Soilborne wheat mosaic virus isolates were imported under United Kingdom license number $\mathrm{PH} / 45 / 1994$. This work was supported by funds from the Scottish Office Agriculture, Environment and Fisheries Department. J. Chen thanks the China National and Zhejiang Provincial Foundation for Natural Sciences 863 Programme (\#101-04-01-05) for their financial support. G. Stubbs was supported by NSF grant MCB-9506204.

\section{LITERATURE CITED}

1. Adams, M. J., Jones, P., and Swaby, A. G. 1988. Purification and some properties of oat golden stripe virus. Ann. Appl. Biol. 112:285-290.

2. Altschuh, D., Lesk, A. M., Bloomer, A. C., and Klug, A. 1987. Correlation of coordinated amino acid substitutions with function in viruses related to tobacco mosaic virus. J. Mol. Biol. 193:693-707.

3. Bahrani, Z., Sherwood, J. L., Sanborn, M. R., and Keyser, G. C. 1988. The use of monoclonal antibodies to detect wheat soil-borne mosaic virus. J. Gen. Virol. 69:1317-1322.

4. Brakke, M. K., and Langenberg, W. G. 1988. Experiences with soilborne wheat mosaic virus in northern America and elsewhere. Pages 183-202 in: Developments in Applied Biology 2: Viruses with Fungal Vectors. J. I. Cooper and M. J. C. Asher, eds. Association of Applied Biologists, Wellesbourne, United Kingdom.

5. Branden, C., and Tooze, J. 1991. Introduction to Protein Structure. Garland Publishing, Inc., New York.

6. Chen, J., and Adams, M. J. 1991. Serological relationships between five fungally transmitted cereal viruses and other elongated viruses. Plant Pathol. 40:226-231.

7. Chen, J., MacFarlane, S. A., and Wilson, T. M. A. 1994. Detection and sequence analysis of a spontaneous deletion mutant of soil-borne wheat mosaic virus RNA 2 associated with increased symptom severity. Virology 202:921-929. 
8. Chen, J., MacFarlane, S. A., and Wilson, T. M. A. 1995. Effect of cultivation temperature on the spontaneous development of deletions in soilborne wheat mosaic furovirus RNA 2. Phytopathology 85:299-306.

9. Chen, J., MacFarlane, S. A., and Wilson, T. M. A. 1995. An analysis of spontaneous deletion sites in soil-borne wheat mosaic virus RNA 2. Virology 209:213-217.

10. Commandeur, U., Koenig, R., Manteuffel, R., Torrance, L., Luddecke, P., and Frank, R. 1994. Location, size and complexity of epitopes on the coat protein of beet necrotic yellow vein virus studied by means of synthetic overlapping peptides. Virology 198:282-287.

11. Devereux, J., Haeberli, P., and Smithies, O. 1984. A comprehensive set of sequence analysis programs for the VAX. Nucleic Acids Res. 12:387395.

12. Dolja, V. V., Boyko, V. P., Agranovsky, A. A., and Koonin, E. V. 1991. Phylogeny of capsid proteins of rod-shaped and filamentous RNA plant viruses: Two families with distinct patterns of sequence and probably structure conservation. Virology 184:79-86.

13. Eisenhaber, F., Persson, B., and Argos, P. 1995. Protein structure prediction: Recognition of primary, secondary and tertiary structural features from amino acid sequence. Crit. Rev. Biochem. Mol. Biol. 30:1-94.

14. Jameson, B. A., and Wolf, H. 1988. The antigenic index: A novel algorithm for predicting antigenic determinants. Comput. Appl. Biosci. 4:181-186.

15. Kraulis, P. J. 1991. MOLSCRIPT: A program to produce both detailed and schematic plots of protein structures. J. Appl. Crystallogr. 24:946-950.

16. Laemmli, U. K. 1970. Cleavage of structural proteins during the assembly of the head of bacteriophage T4. Nature (Lond.) 227:680-685.

17. Namba, K., Pattanayek, R., and Stubbs, G. 1989. Visualization of protein-nucleic acid interactions in a virus. Refinement of intact tobacco mosaic virus structure at $2.9 \AA$ resolution by fiber diffraction. J. Mol. Biol. 208:307-325.
18. Pereira, L. G., Torrance, L., Roberts, I. M., and Harrison, B. D. 1994. Antigenic structure of the coat protein of potato mop-top furovirus. Virology 203:277-285.

19. Roberts, I. M., Robinson, D. J., and Harrison, B. D. 1984. Serological relationships and genome homologies among geminiviruses. J. Gen. Virol. $65: 1723-1730$.

20. Shirako, Y., Ali, I., and Wilson, T. M. A. 1990. Nucleotide sequence of soil-borne wheat mosaic virus RNA II. (Abstr.) Phytopathology 80:1018.

21. Shirako, Y., and Brakke, M. K. 1984. Two purified RNAs of soil-borne wheat mosaic virus are needed for infection. J. Gen. Virol. 65:119-127.

22. Shirako, Y., and Brakke, M. K. 1984. Spontaneous deletion mutation of soil-borne wheat mosaic virus RNA II. J. Gen. Virol. 65:855-858.

23. Shirako, Y., and Wilson, T. M. A. 1993. Complete nucleotide sequence and organization of the bipartite RNA genome of soil-borne wheat mosaic virus. Virology 195:16-32.

24. Thomas, J. E., Massalski, P. R., and Harrison, B. D. 1986. Production of monoclonal antibodies to African cassava mosaic virus and differences in their reactivities with other whitefly-transmitted geminiviruses. J. Gen. Virol. 67:2739-2748

25. Torrance, L. 1992. Serological methods to detect plant viruses: Production and use of monoclonal antibodies. Pages 7-33 in: Techniques for the Rapid Detection of Plant Pathogens. J. M. Duncan and L. Torrance, eds. Blackwell Scientific Publications, Oxford.

26. Torrance, L. 1992. Analysis of epitopes on potato leafroll virus capsid. Virology 191:485-489.

27. Torrance, L., Cowan, G. H., and Pereira, L. G. 1993. Monoclonal antibodies specific for potato mop-top virus and some properties of the coat protein. Ann. Appl. Biol. 122:311-322.

28. Torrance, L., Pead, M. T., and Buxton, G. 1988. Production and some characteristics of monoclonal antibodies against beet necrotic yellow vein virus. Ann. Appl. Biol. 133:519-530. 